\title{
Research on Intelligent Agriculture Greenhouses Based on Internet of Things Technology
}

\author{
Ying SHANG ${ }^{a}$ and An-Ying FU \\ Shaanxi Institute of International Trade \& Commerce, Xi'an 712046, China
}

\begin{abstract}
Internet of things is a hot topic in the field of research, get a lot of attention, On behalf of the future development trend of the network, Internet of Things has a wide range of applications, because of the efficient and reliable information transmission in modern agriculture. In the greenhouse, the conditions of the Greenhouse determine the quality of crops, high yield and many other aspects. Research on Intelligent Agriculture Greenhouses based on Internet of Things, mainly Research on how to control the conditions of the greenhouses, So that the indoor conditions suitable for crop growth. In the pater, we study of Zigbee technology, Designed the solar power supply module, greenhouse hardware and software part, And the system was tested by experiment, The analysis of the experimental data shows that the system can provide good conditions for the growth of crops to achieve the high yield and high quality of crops.
\end{abstract}

\section{Introduction}

In modern agricultural production, the control of the surroundings of crops is an important part of improving crop quality. Greenhouse environment and biological growth are closely related, Environmental monitoring is assurance, achieve the greenhouse automation, scientific, In system study, we can analyze the testing data, Combined with crop growth regular pattern, Control environmental conditions, So that achieve the purposes of crops high quality, high yield and efficient cultivation. Intelligent Agriculture Greenhouses Based on Internet of Things Technology, Combined with the current emerging Internet of Things technology, which can achieve the goals, efficient and reasonable use of various agricultural resources and improve the environment of this sustainable development. Can maximize the agricultural real productivity, Is an effective way to achieve high quality, high yield, low consumption and environmental protection of sustainable development of agriculture[1].

\section{System composition}

The system includes data acquisition sensor terminal, heating equipment, ventilation equipment, control terminal, Zigbee wireless communication network terminal, monitoring center and other components, System block diagram shown in Figure 1.

\footnotetext{
${ }^{a}$ Corresponding author: 81593866@qq.com
} 


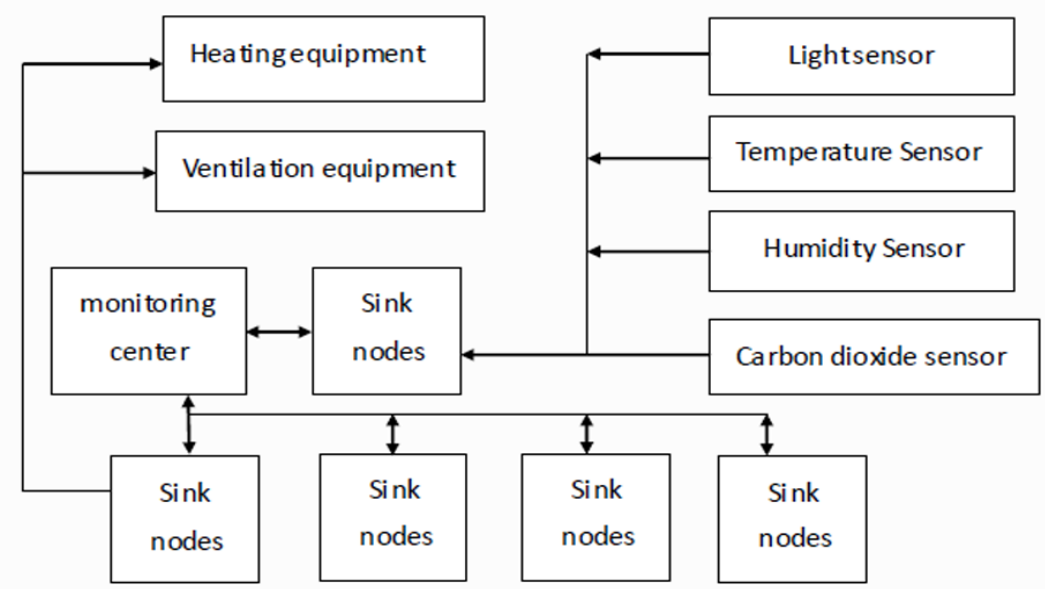

Figure 1. System block diagram

\section{System hardware design}

\subsection{Zigbee technology}

In the system, the acquisition node and the sink node processor adopt the Zigbee technology chip cc2530. The CC2530 is a true system-on-chip solution for IEEE 802.15.4, Zigbee and RF4CE applications. It enables robust network nodes to be built with very low total bill-of-material costs. The C2530 combines the excellent performance of a leading RF transceiver with an industry-standard enhanced $8051 \mathrm{MCU}$, in-system programmable flash memory, 8-KB RAM, and many other powerful features. The CC2530 comes in four different flash versions: C2530F32/64/128/256, with $32 / 64 / 128 / 256 \mathrm{~KB}$ of flash memory, respectively. The CC2530 has various operating modes, making it highly suited for systems where ultralow power consumption is required. Short transition times between operating modes further ensure low energy consumption[2].

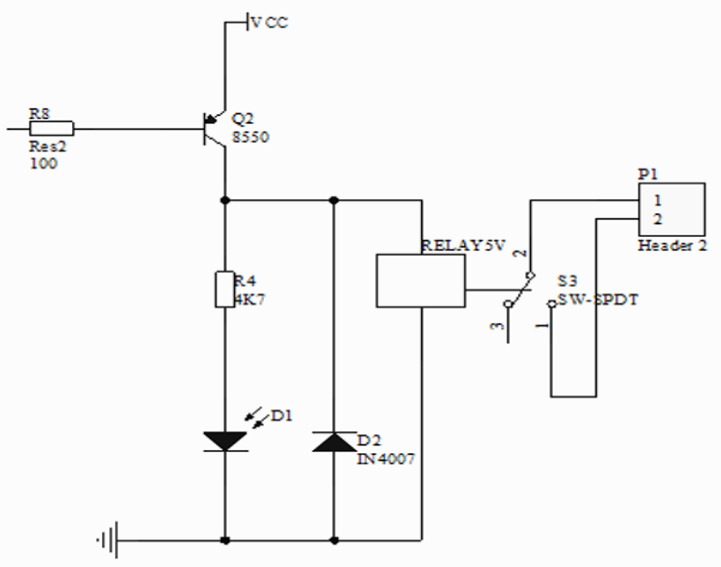

Figure 2. CC2530 Application Circuit 


\subsection{System power supply}

Based on the Internet of Things intelligent agricultural greenhouses use dual supply that power supply system solar and electric power. Green is an advantage of the design; Greenhouses are usually located in relatively open fields, there is no shelter around, Very suitable for solar power supply. The designing of the solar power supply system use ST-150P solar panels, About two square feet, The system can automatically rotate and capture sunlight according to the sun's light intensity, To maximize the use of sunlight, The overall block diagram of the power supply system is shown in Figure 3.

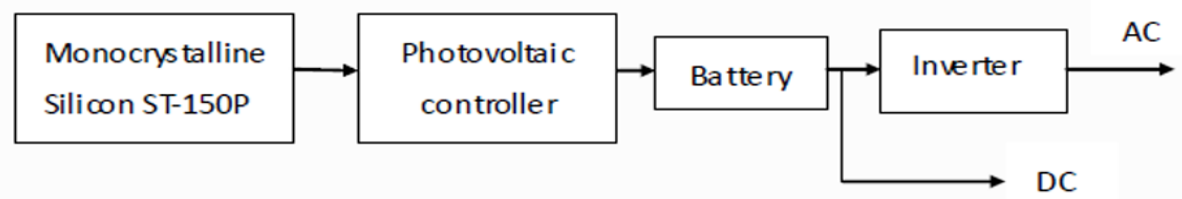

Figure 3. Solar power supply system block diagram

There are four photosensitive resistors around the center of the installation in the electromagnetic plate, Divided into two groups, The photoresistor is used to collect light intensity, And then the light intensity signal into a voltage signal for comparison, According to the size of the voltage signal, The motor determines the direction of rotation and the angle of rotation[3].

\subsection{Temperature and humidity control}

The temperature and humidity control section mainly monitors the temperature and humidity. First set the normal temperature threshold of the temperature and humidity, When the current temperature or humidity is not in the normal threshold range, The sink node will send the data to the monitoring center, According to the instruction, the monitoring center makes the corresponding processing. When the temperature is higher than the normal threshold, Start fan exhausting function; When the temperature is below the normal threshold, Start heating equipment for heating, A constant temperature is maintained after reaching the normal threshold. When the humidity is higher than the normal threshold, Start the exhaust fan; when the humidity is below the normal threshold, Start the watering equipment to water[4]. The circuit is shown in Figure 4.

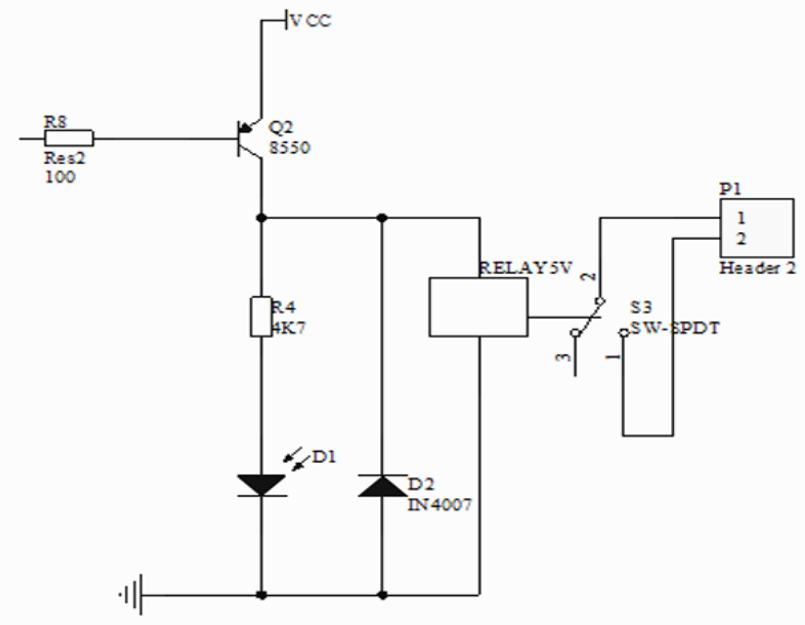

Figure 4. Temperature and humidity control circuit 


\subsection{Switch ventilation window}

In the system, In addition to has a temperature and humidity control circuit there are also contains a photosensitive sensor, In real time, the light sensor can detect the intensity of light in the greenhouse, So that the signal through the AD conversion and the signal will be collected to the CPU,CPU to do processing, Thereby controlling the actuator to open and close the ventilation window[5-7]. The circuit is shown in Figure 5.

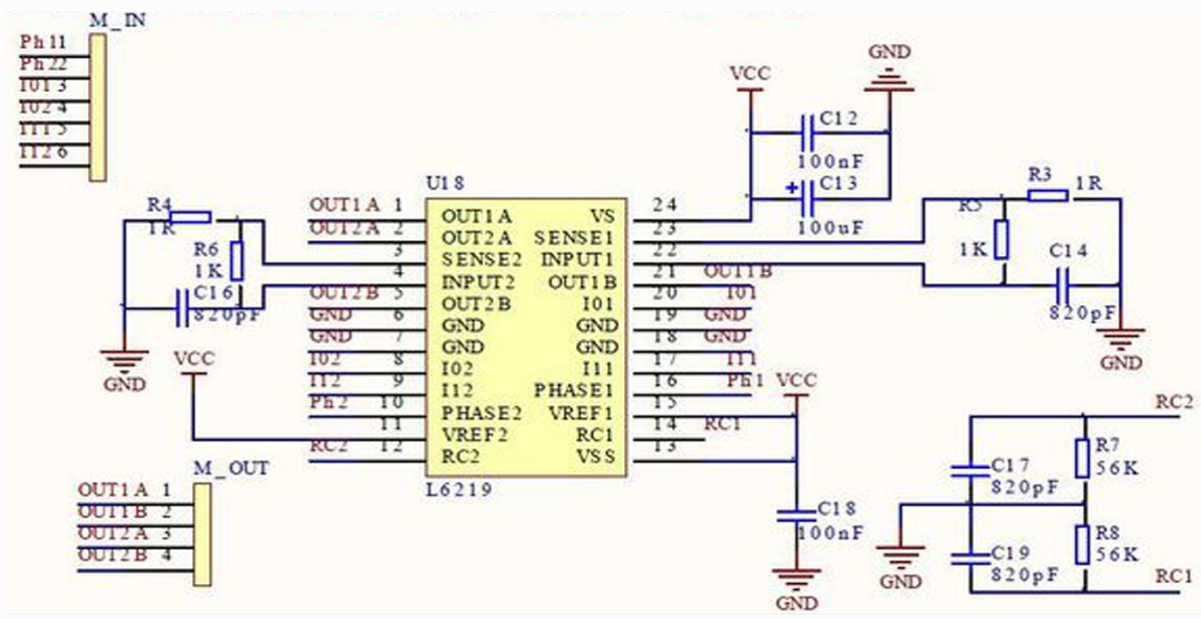

Figure 5. Switch ventilation window circuit

\section{System software design}

In the greenhouse the temperature and humidity sensors to collect temperature and humidity data at various points, The data is recorded at regular intervals. And converted into analog data, the date transfer to the CUP for processing, The supervisory control is controlled according to the received data status, And then record and transfer[8-9].

When the temperature and humidity is not in the normal region, System startup related processing scheme. Power on and to initialize each variable, set the parameters by pressing the key, Then compares the data that the temperature and humidity sensor collected with the value set by the key, In order to achieve the corresponding action[10-11]. The acquisition data and control flow chart are shown in Figure 5 and Figure 6. 

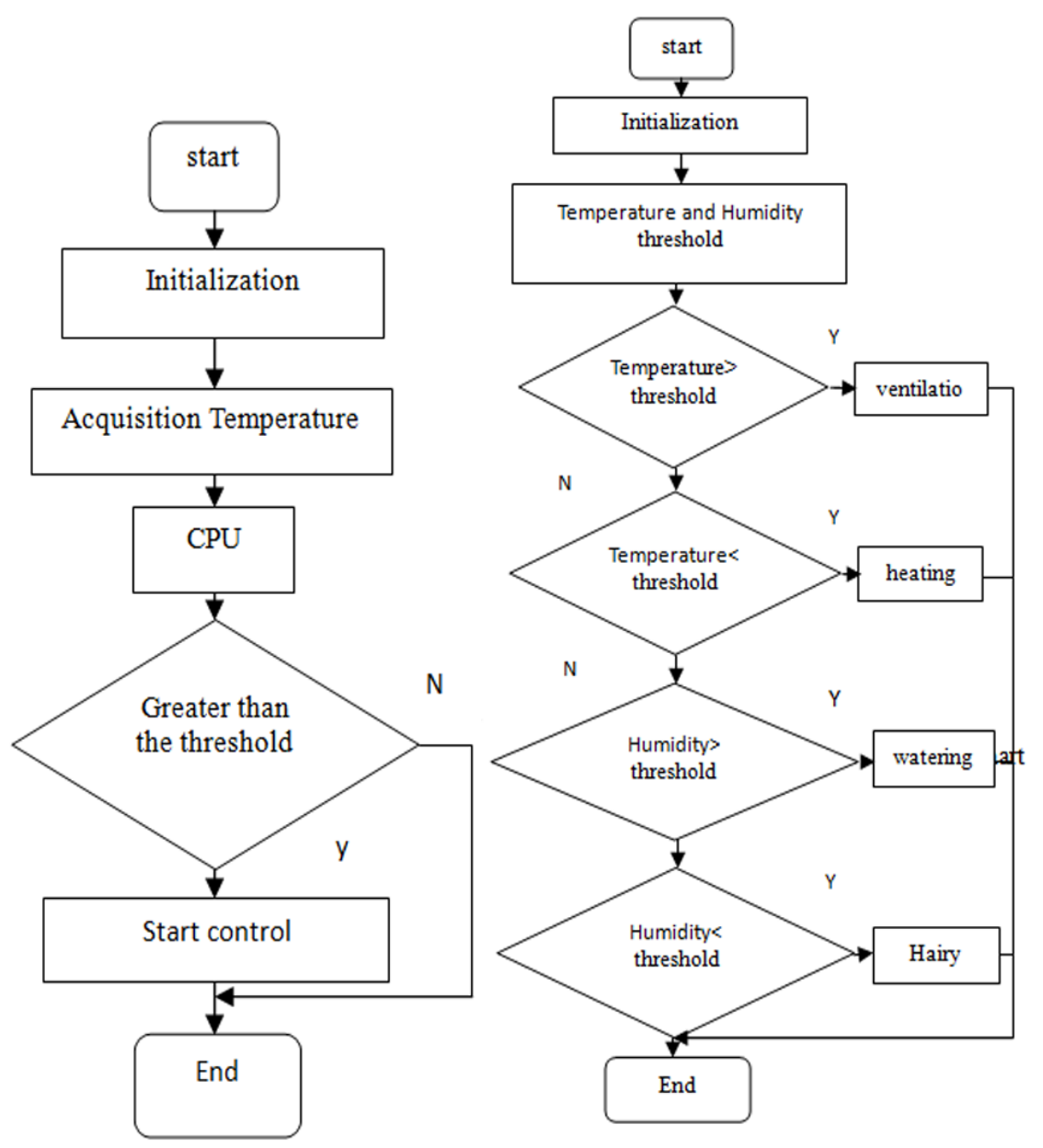

Figure 5. A flow chart for collecting data

Figure 6. Temperature and humidity control flow chart

\section{Test results and analysis}

In the system testing phase, Selected a farmhouse measure, the farmhouse in Yulin, At the same time, In the measurement process use a special measurement instrument measurement, Each set of measurement data is spaced 10 minutes, The measurement results are shown in Table 1 and Table 2 . 
Table 1. The testing results of the Study system

\begin{tabular}{|c|c|c|c|c|c|}
\hline number & $\begin{array}{c}\text { Air } \\
\text { temperature }\end{array}$ & Air humidity \% & $\begin{array}{c}\text { Soil } \\
\text { temperature }\end{array}$ & Soil moisture \% & $\begin{array}{c}\text { CO2 concentration } \\
(\mathrm{PPM})\end{array}$ \\
\hline 1 & $21.3^{\circ} \mathrm{C}$ & 29.1 & 25.5 & 3000.1 & 441 \\
\hline 2 & $21.6^{\circ} \mathrm{C}$ & 29.1 & 25.6 & 3000.2 & 444 \\
\hline 3 & $21.6^{\circ} \mathrm{C}$ & 29.3 & 25.7 & 3000.2 & 449 \\
\hline 4 & $21.7^{\circ} \mathrm{C}$ & 30.0 & 25.8 & 2999.2 & 455 \\
\hline 5 & $21.9^{\circ} \mathrm{C}$ & 30.1 & 26.9 & 2999.1 & 459 \\
\hline 6 & $21.9^{\circ} \mathrm{C}$ & 30.1 & 27.1 & 3000.2 & 467 \\
\hline 7 & $22.1^{\circ} \mathrm{C}$ & 29.1 & 29.5 & 3001.2 & 471 \\
\hline 8 & $22.2^{\circ} \mathrm{C}$ & 29.2 & 27.8 & 3005.1 & 473 \\
\hline 9 & $23.1^{\circ} \mathrm{C}$ & 30.1 & 28.2 & 3010.1 & 482 \\
\hline 10 & $23.5^{\circ} \mathrm{C}$ & 30.0 & 28.9 & 3011.2 & 491 \\
\hline
\end{tabular}

Table 2. The testing results of the Dedicated testing tools

\begin{tabular}{|c|c|c|c|c|c|}
\hline number & $\begin{array}{c}\text { Air } \\
\text { temperature }\end{array}$ & $\begin{array}{c}\text { Air } \\
\text { humidity } \%\end{array}$ & $\begin{array}{c}\text { Soil } \\
\text { temperature }\end{array}$ & Soil moisture \% & $\begin{array}{c}\text { CO2 concentration } \\
(\text { PPM })\end{array}$ \\
\hline 1 & $20.3^{\circ} \mathrm{C}$ & 28.1 & 25.2 & 2999.1 & 439 \\
\hline 2 & $20.5^{\circ} \mathrm{C}$ & 28.1 & 25.2 & 2995.2 & 442 \\
\hline 3 & $20.6^{\circ} \mathrm{C}$ & 28.2 & 25.3 & 2991.2 & 448 \\
\hline 4 & $20.5^{\circ} \mathrm{C}$ & 29.0 & 25.5 & 2988.2 & 452 \\
\hline 5 & $20.6^{\circ} \mathrm{C}$ & 29.0 & 26.1 & 2995.1 & 458 \\
\hline 6 & $20.7^{\circ} \mathrm{C}$ & 29.0 & 26.5 & 2999.2 & 465 \\
\hline 7 & $21.3^{\circ} \mathrm{C}$ & 28.0 & 26.9 & 3000.2 & 469 \\
\hline 8 & $21.8^{\circ} \mathrm{C}$ & 29.0 & 27.1 & 3004.1 & 472 \\
\hline 9 & $22.1^{\circ} \mathrm{C}$ & 29.2 & 27.9 & 3009.1 & 480 \\
\hline 10 & $22.5^{\circ} \mathrm{C}$ & 29.3 & 28.2 & 3010.2 & 489 \\
\hline
\end{tabular}

Through the above data analysis, the data results that using a dedicated test tool to measure are higher than the testing value that test in the research system. The comprehensive analysis shows that the system under study has a certain delay in the actual measurement, The measured data is measured after the actual time. But the overall measurement results are close to the actual value, the error is very small.

\section{Conclusions}

In this paper, intelligent agriculture greenhouses were studied, The Zigbee technology can be used in the system design, The system can collect the temperature and humidity data, $\mathrm{CO} 2$ concentration, etc. Intelligent agriculture greenhouses have heating function, Can be heat to the greenhouse, as same as the human warm, So that the temperature inside the greenhouse is more suitable for crop growth, to achieve high yield, high quality to the purpose. Furthermore, the dual power supply used in the system, Power and solar dual power supply. Through analysis the testing data, The system test error is very small, Can be applied in practice. In the follow-up study, Will continue to study the system, Further reducing the measurement error.

\section{Acknowledgment}

This work is supported by the Scientific Research Project of Education Department of Shaanxi Province Government (2016JK2038). 


\section{References}

1. Ya-Di LI, MIAO Teng, ZHU Chao, JI Jianwei. J. Agric Sci Tech China18,94(2016)

2. Lin-Li Guo. D. HLJU.(2015)

3. Shi-Hong LI. J. E World,66(2016)

4. Zhi-Bo Lin. J. Autom Inf Eng, 36,19(2015)

5. Hong-Ye Yang.J. JS Agricultural Sciences,44,401(2016)

6. Xiao-Tao Zhang. J. New Technology \& New Process, 10,20(2016)

7. Jie-Rong Zhao.J. Journal of Dalian Polytechnic University,35,373(2016)

8. Li-Ying Han.J. Journal of Chinese Agricultural Mechanization,37,65(2016)

9. Hua Ren.J. Intelligent Processing and Application,6,66,(2014)

10. Kai-Sheng Zhang.J. Journal of xi' an university of science and technology,35,805(2015)

11. Xin-Hao Zhu. Comput Eng Appl,11,244,(2015) 